\title{
LA LÓGICA DEL MERCADO EN LAS PRIMERAS REFLEXIONES DE DANTE SOBRE LA ECONOMÍA
}

\section{Market Logic in Dante's First Reflections on the Economy}

\author{
Raffaele Pinto
}

\section{Resumen}

El artículo sondea los primeros acercamientos de Dante al tema económico, en su etapa florentina: en las dos canciones doctrinales (Le dolci rime d'amor ch'io solea, Poscia ch'Amor del tutto m'ha lasciato) y el poema Fiore. Vemos aquí los atisbos de la crítica del capitalismo que será desarrollada en las obras de la madurez.

Palabras clave

Codicia; economía política medieval; mercado, mercancía

\begin{abstract}
This article probes Dante's first approaches to economic issues in his early life in Florence, in two songs, 'Le dolci rime d'amor ch'io solea' and 'Poscia ch'Amor del tutto m'ha lasciato', and the poem 'Fiore'. Here we see glimpses of a critique of capitalism that will be developed in Dante's mature works.
\end{abstract}

Keywords

Avarice; market; medieval political economy; merchandise

Las primeras observaciones de Dante sobre la nueva economía monetaria que está transformando con ritmo vertiginoso la sociedad florentina se encuentran en los textos posteriores a la Vida Nueva y a la polémica suscitada por Cavalcanti con la canción Donna me prega, polémica que induce Dante a infringir la restricción que él mismo 
había impuesto a la poesía en vulgar: hablar exclusivamente del amor (cap. XXV1). Las leemos en la primera canción doctrinal (Le dolci rime d'amor ch'io solea), en la que se niega que las riquezas puedan ser fundamento de la nobleza porque son, por su propia naturaleza, 'imperfectas' (o sea, incapaces de satisfacer el deseo que movilizan); luego, en la segunda doctrinal (Poscia ch'amor del tutto m'ha lasciato), en la que el poeta describe las perversas transformaciones de los comportamientos que la lógica del mercado produce $^{2}$; y finalmente en el Fiore, en que es denunciado, por un lado, el poder socialmente y globalmente transformador de dicha lógica, $\mathrm{y}$, por el otro, la legitimación ideológica que a ella proporciona el orden clerical ${ }^{3}$.

\section{Le dolci rime, 21-60}

Tale imperò che gentilezza volse, secondo il suo parere, che fosse antica possession d'avere... ché le divizie, sì come si crede, non posson gentilezza dar né torre, però che vili son da lor natura... Che siano vili appare ed imperfette, ché, quantunque collette, non posson quïetar, ma dan più cura; onde l'animo ch'è dritto e verace per lor disfacimento non si sface.

\footnotetext{
${ }^{1}$ «Lo que movió al primero de todos ellos [los poetas en lengua vulgar] a versificar en lengua vulgar fue el deseo de que entendiera sus palabras una mujer a quien se le hacían de difícil entendimiento los versos latinos. Digo esto en contra de quienes riman sobre materia no amorosa, siendo así que tal manera de expresarse fue inventada, en un principio, para hablar de Amor».

${ }^{2}$ Umberto Carpi ha reconstruido magistralmente la corriente de opinión que en Toscana, y sobre todo en Florencia, denunciaba, tanto en prosa como en verso, la difusión de la economía monetaria, y ha indicado en Monte Andrea (banquero arruinado y poeta) el más radical de los teóricos del derrumbamiento de los valores sociales tradicionales, de forma tal que puede amargamente declarar que la única nobleza que cuenta de verdad es la que proporciona el florín (la moneda de oro acuñada en Florencia) - La nobiltà di Dante, Firenze, Edizioni Polistampa, 2004, pp. 11-321. En lo que concierne a Monte Andrea, véase también Borsa, P., Poesia e politica nell'età di Dante, Milán, Ledizioni, 2017, pp. 3750. Sobre la cuestión económica en Dante señalo, además, el volumen del Grupo Tenzone dedicado a la canción Doglia mi reca ne lo core ardire ('La biblioteca di Tenzone', 2008).

${ }^{3}$ Advierto preliminarmente que considero la redaccion del Fiore posterior a la Vida Nueva y, por lo tanto, también a los 'Ordinamenti di giustizia' (1293), y posterior además a la elección al Papado de Bonifacio VIII (24 diciembre del 1294), pero anterior, obviamente, al exilio (sobre el lugar que ocupa el Fiore en el conjunto cronológicamente ordenado de la obra de Dante, y sobre su significado global, remito a mi artículo Uno snodo eterodosso nella storia della poesia di Dante: il 'Fiore' en N. Tonelli (ed.), Sulle Tracce del Fiore, Florencia, Le Lettere, 2016, pp. 159-190).
} 
[Hubo un Emperador que gentileza, según su opinión, quiso

que fuese antigua posesión de bienes...

que las riquezas, aunque así se opine, no pueden dar ni quitar gentileza, porque son viles por naturaleza... Se prueba que son viles e imperfectas porque aunque se acumulen no dan quietud, provocan nuevas ansias; así que un temple fuerte y verdadero por quedarse sin ellas no se inmuta].

La 'imperfección' de las riquezas depende del hecho de que, como se argumenta de manera más extensa en el IV Trattato del Convivio, su adquisición no tiene un término, y tiende falsamente $y$, de manera antinatural, hacia el infinito, ya que «in loco di bastanza, recano nuovo termine» (xii 5), lo que convierte su deseo en insaciable (frente al deseo de conocimiento, que es natural y perfecto, dado que tiene límites, y, dentro de estos límites, satisfacción).

Dante leía esta idea en la Política de Aristóteles, que en el primer Libro distingue entre la riqueza representada por valores de uso (o sea los bienes que son necesarios para la supervivencia material de la familia o de la ciudad), que él entiende como 'económica', y la riqueza representada por valores de cambio (o sea el dinero), que él entiende como 'crematística': los primeros tienen un límite natural (la satisfacción de las necesidades vitales), los segundos, en cambio, son potencialmente ilimitados, y por consiguiente no son naturales. Marx, en el primer Libro del Capital (II iv), cita ampliamente de los caps. 8-9 del primer Libro de la Política; entre otros, estos pasajes:

La verdadera riqueza está formada por éstos [los bienes necesarios a la vida] porque la provisión de estos bienes en cantidad suficiente no es ilimitada... Pero existe otro tipo de arte adquisitivo, a lo que se suele llamar generalmente, y es apropiado llamarlo así, 'crematística', por el cual parece que no existe límite alguno a la riqueza ni a la propiedad. Muchos consideran que existe tan sólo un tipo, y que es el mismo arte adquisitivo, a causa de su afinidad con él. Ni es el mismo que el mencionado [el 'económico'] ni está lejos de aquél; pero de los dos, el primero, es por naturaleza, y este segundo no... ${ }^{4}$

Santo Tomás, a la zaga del Filósofo, niega que el dinero sea riqueza, y comenta de esta manera (Sententia Politic., lib. 1 1. 7 n. 11):

${ }^{4}$ Llama la atención que la crítica de Aristóteles de la riqueza monetaria tenga como argumento también el riesgo representado por la devaluación, siempre posible, del valor de la moneda: «Otras veces se advierte que el dinero es una bagatela y completamente convencional, y nada por naturaleza, porque si cambian las normas convencionales no vale nada ni es de utilidad para nada de lo necesario, y muchas veces, uno que es rico por su dinero, llega a carecer del sustento indispensable. Así que bien extraña es esta riqueza, en cuya abundancia se perece de hambre, como cuentan en el mito de aquel Midas que al cumplirse su deseo convertía en oro todo lo que tocaba» (I,9). 
Deinde cum dicit propter quod quaerunt etc., concludit determinationem veritatis; et dicit quod illi qui recte sapiunt, propter praedictas rationes dicunt aliud esse divitias et pecuniam, sive pecuniativam: sunt enim quaedam divitiae secundum naturam, scilicet de rebus necessariis ad vitam, sicut supra dictum est; et talis acquisitio divitiarum proprie pertinet ad oeconomicam: sed illa pecuniativa quae est campsoria multiplicat pecunias non omnibus modis, sed solum per denariorum permutationem: unde tota consistit circa denarios: quia denarius est principium et finis talis commutationis, dum denarius pro denario datur. Patet igitur secundum hoc, quod ditiores sunt qui abundant in rebus necessariis ad vitam vere loquendo, quam illi qui abundant in denariis.

[Los que saben, dicen que son cosas distintas las riquezas y el dinero, o la riqueza monetaria: algunas riquezas lo son por naturaleza, en tanto que cosas necesarias a la vida; la adquisición de este tipo de riquezas forma parte de la economía; la monetaria, en cambio, que procede de la venta, multiplica el dinero no de cualquier manera, sino solo por una permutación pecuniaria, y por lo tanto consiste exclusivamente en el dinero, dado que el dinero es el principio y el fin de este intercambio, puesto que el dinero se da por dinero. Es evidente, entonces, que son verdaderamente más ricos los que tienen abundancia de bienes necesarios a la vida, y no los que tienen abundancia de dinero].

Las «divitiae secundum naturae», o sea los bienes necesarios a la supervivencia, configuran la economía de una comunidad según criterios de justicia y racionalidad (tal como se explica con gran despliegue de argumentos, en el V Libro de Ética Nicomaquea ${ }^{5}$ ); luego están las riquezas que proceden del intercambio finalizado a la produc-

${ }^{5}$ De suma importancia, por la resonancia que tendrá en Dante, a partir del Convivio, es la distinción que establece aquí Aristóteles entre la justicia legal o distributiva (a communi ad singulos) y la justicia particular o conmutativa (ab uno in alterum). Asì comenta S. Tomás (Sententia Ethic. V, 1. 4 n. 1): «Primo proponit unam speciem particularis iustitiae. Et dicit, quod una species eius, et similiter iusti, quod secundum ipsam dicitur, est illa, quae consistit in distributionibus aliquorum communium, quae sunt dividenda inter eos qui communicant civili communicatione: sive sit honor, sive sit pecunia, vel quicquid aliud ad bona exteriora pertinens, vel etiam ad mala; sicut labor, expensae et similia. Et quod hoc pertineat ad particularem iustitiam, probat, quia in talibus contingit accipere (unius ad alterum) aequalitatem vel inaequalitatem unius ad alterum, quae pertinent ad iustitiam vel iniustitiam particularem, ut supra dictum est. Secundo ibi: una autem etc., ponit secundam speciem particularis iustitiae. Et dicit, quod una alia species particularis iustitiae est, quae constituit rectitudinem iustitiae in commutationibus, secundum quas transfertur aliquid $a b$ uno in alterum; sicut prima species iustitiae attendebatur secundum quod transfertur aliquid $a$ communi ad singulos» (S. Thomae Aquinatis In decem libros Ethicorum Aristotelis ad Nicomachum expositio, Cura et studio P. Fr. R.S. Spiazzi, O. P., Taurini - Romae, Marietti, 1964). [Sobre el primer punto, presenta una especie de la justicia particular. Una de sus especies que es también una especie de lo justo que se dice según la justicia particular, es la que consiste en la distribución de algunas cosas comunes que deben repartirse entre los que forman parte de la comunidad cívica, como el honor, el dinero, o cualquier otra concerniente a los bienes exteriores; o a los males, como los trabajos los gastos o desembolsos, etc. Prueba que esto pertenece a justicia particular, porque en tales casos acontece tomar entre uno y otro una igualdad o bien una desigualdad, lo que compete a la justicia 
ción de dinero, en el sentido de que el dinero es el principio y el fin del intercambio; por esto propiamente ricos son solo los que disponen en abundancia de bienes necesarios a la vida.

La identificación de la nobleza con la antigua riqueza se explica, en Aristóteles, a partir de esta distinción, por la que se entiende por riqueza no el dinero, sino la propiedad de la tierra, fundamento no solo de la riqueza de bienes materiales sino también del poder, lo que vale tanto para la antigüedad como para en la Edad Media feudal. Aristóteles, y con él S. Tomás, describen los dos modelos de intercambio económico: el precapitalista o feudal, o sea 'mercancía - dinero - mercancía' (en que la finalidad es la adquisición de valores de uso) y el capitalista o de mercado, o sea 'dinero mercancía - dinero' (en que la finalidad es el valor de cambio) ${ }^{6}$. Según el modelo historiográfico clásico, la circulación del dinero y la economía de mercado vuelven a aparecer en Europa después del año 1000, cuando condiciones de vida menos turbulentas y cierto desarrollo tecnológico en la agricultura crean excedencias, en relación con las necesidades de supervivencia de la población; estas excedencias son el motor del mercado y del desarrollo económico. La economía feudal en sentido estricto, en cambio, no crea excedencias, y en su marco, por lo tanto, no hay desarrollo, o, al menos, no hay un desarrollo suficientemente significativo como para poner en entredicho el sistema de poder tradicional, basado en la posesión de la tierra: el feudo, en efecto, no es solo la propiedad, antes vitalicia luego hereditaria, sobre un territorio, sino también una red de relaciones a la vez políticas, jurídicas y económicas. Frente a este tipo di riqueza, sustancial porque abarca mucho más que los bienes materiales, la riqueza de tipo 'crematístico', que consiste exclusivamente en el dinero, es algo marginal y aleatorio (o, incluso perverso, cuando se busca la felicidad en su posesión, que es el pecado de la avaricia). Ahora bien, mientras Aristóteles y S. Tomás distinguen entre una riqueza legítima y verdadera, o sea la posesión de la tierra, que implica una amplia disponibilidad de valores de uso, y una riqueza falsa que se basa en el dinero y en la lógica del mercado, Dante neutraliza la distinción, y considera como riqueza solo la que está finalizada a la producción de dinero, como si la otra no existiera. Obsérvese, en los versos citados, que de las riquezas, consistentes, según el Emperador, en «antica possession d'avere» (que solo puede ser tierra y derechos feudales), se dice que «quantunque collette, / non posson quïetar, ma dan più cura», lo que tiene sentido solo si se

o a la injusticia particular, como se ha dicho. En segundo lugar, presenta una segunda especie de justicia particular. Es la que constituye la rectitud de la justicia en las conmutaciones, según las cuales se trasfiere algo de uno a otro; así como en la primera especie de justicia la rectitud se alcanzaba en la transferencia de algo de lo común a los particulares] - Tomás de Aquino, Comentario a la Ética a Nicómaco de Aristóteles, traducción A. Mallea; estudio preliminar y notas C.A. Lértora Mendoza, Pamplona, EUNSA, 2001.

${ }^{6}$ Enrico Fenzi explica perfectamente, a partir del análisis de Marx, en el Capital, la diferencia entre los dos circuitos (Tra etica del dono e accumulazione, en Grupo Tenzone, op. cit., pp. 175-178, ahora en Le canzoni di Dante, Florencia, Le Lettere, 2017, pp. 501-546). 
habla, aristotélicamente, de 'crematística', o sea de dinero, cuya acumulación, en la lógica del capital, y como Aristóteles denuncia, no tiene límites que se puedan fijar.

Es evidente que a sus ojos la economía de mercado ya ha sustituido completamente la economía 'natural' y feudal y es una evolución irreversible que tiene en las ciudades (Florencia, en particular) su centro propulsor. Sus efectos negativos pueden como mucho ser mitigados, a través de una reforma 'virtuosa' de la mentalidad y los comportamientos del Popolo (florentino) que de ella vive; y este es, justamente, el programa de reforma moral de la burguesía florentina propuesto y teorizado en las dos canciones doctrinales. Pero, y en esto vemos la agudeza extraordinaria de su análisis, el proceso de sustitución de un tipo de economía, y de riqueza, a otro, es irreversible. Como resultará muy claro en las obras escritas en el exilio, la eliminación de las anomalías del capitalismo no implica una vuelta al sistema económico feudal, sino un control racional sobre la distribución de la riqueza, que debe responder a criterios de justicia (como ya había explicado Aristóteles) en el marco de una organización política global (que en cambio estaba fuera del horizonte intelectual del Filósofo), en la que los diferentes sujetos económicos estén firmemente disciplinados desde un poder universal superior (el Imperio).

Pero la pregunta a la que hay que dar una respuesta es la siguiente: ¿por qué Dante (que obviamente conoce muy bien tanto las obras aristotélicas de argumento económico-político, o sea la Política y la Ética, como los comentarios tomísticos) atribuye al Emperador una teoría sobre la nobleza que éste (Federico II, que era también rey de Sicilia) nunca ha formulado? Considérese, además, que por su política fuertemente centralizadora, el Emperador debía tener una idea bastante negativa de la antigua aristocracia del Reino. Su hijo Manfredi, en efecto, perdió el reino y la vida, en la guerra con los angevinos que el Papa había llamado en Italia para que le echaran de Sicilia, por la traición de los barones del sur de Italia, que veían en los franceses una garantía al mantenimiento de sus privilegios feudales.

Hay que tener en cuenta que cuando escribe esta canción, Dante es hombre del 'Comune' de Florencia, donde el 'Popolo' (o sea los grupos económicamente dominantes), en los años '90 del siglo XIII, había ocupado los principales cargos de gobierno de la ciudad, prácticamente expulsando de ellos la aristocracia feudal: los 'Ordinamenti di Giustizia', con los que se obligaba a todos lo que quisieran ocupar cargos públicos a matricularse en una de las corporaciones, 'Arti', entre las que la ciudadanía estaba repartida, son de 1293. La carrera política de Dante empieza en 1295, y es inmediatamente acompañada por la dura polémica en contra de la ideología de estos grupos sociales, de la que este texto es el primer ejemplo. En el Convivio, Dante tendrá palabras de hondo desprecio hacia las 'populari persone' que, ocupadas toda su vida en algún oficio, están completamente desprovistas de luz intelectual (I xi 6-7):

De l'abito di questa luce discretiva massimamente le populari persone sono orbate; però che, occupate dal principio de la loro vita ad alcuno mestiere, dirizzano sì l'animo loro a quello per forza de la necessitate, che ad altro non intendono. E però che 
l'abito di vertude, sì morale come intellettuale, subitamente avere non si può, ma conviene che per usanza s'acquisti, ed ellino la loro usanza pongono in alcuna arte e a discernere l'altre cose non curano, impossibile è a loro discrezione avere ${ }^{7}$.

[De esa luz del discernimiento carece, particularmente, la mayoría de las personas populares, porque, obligadas por la necesidad, ponen toda su atención en el oficio que les ocupa desde el comienzo de sus vidas, de manera que no atienden a nada más. Y dado que el hábito de la virtud, ya sea moral o intelectual, no se adquiere en poco tiempo, sino que requiere la práctica -cosa que ellos dedican al aprendizaje de alguna arte y no se preocupan de reflexionar sobre las demás cosas- resulta imposible que adquieran la facultad del discernimiento].

La misma crítica de la división en Artes de la ciudadanía se vislumbra en la alegoría de Babel del De vulgari eloquentia (en la que vuelve el tema del lenguaje amenazado en su función social y comunicativa por la ceguera, o soberbia, del 'Popolo') -I vii 6-7:

Siquidem pene totum humanum genus ad opus iniquitatis coierat: pars imperabant, pars architectabantur, pars muros moliebantur, pars amussibus regulabant, pars trullis linebant, pars scindere rupes, pars mari, pars terra vehere intendebant, partesque diverse diversis aliis operibus indulgebant; cum celitus tanta confusione percussi sunt ut, qui omnes una eademque loquela deserviebant ad opus, ab opere multis diversificati loquelis desinerent et numquam ad idem commertium convenirent. Solis etenim in uno convenientibus actu eadem loquela remansit: puta cunctis architectoribus una, cunctis saxa volventibus una, cunctis ea parantibus una; et sic de singulis operantibus accidit. Quot quot autem exercitii varietates tendebant ad opus, tot tot ydiomatibus tunc genus humanum disiungitur; et quanto excellentius exercebant, tanto rudius nunc barbariusque locuntur ${ }^{8}$.

[Pues casi todo el género humano se había reunido para llevar a cabo su maligna empresa: unos dirigían las obras, otros hacían los proyectos, otros levantaban los muros, otros los cuadraban, otros los encalaban, otros rompían las rocas, otros las trasladaban, por mar y por tierra, y grupos distintos se dedicaban a otras distintas tareas. Entonces desde lo alto del cielo fueron sacudidos por una confusión tan grande que todos ellos, que hasta ahora colaboraban hablando una misma lengua, tuvieron que abandonar el trabajo porque habían sido diversificados en una multitud de lenguas, y ya no pudieron colaborar en la obra común. En efecto conservaron una misma lengua solo los que hacían el mismo trabajo: es decir, una lengua para todos los arquitectos, otra para los que empujaban las rocas, otra para los que las cuadraban, y así sucesivamente para cada grupo de trabajadores. Cuantas eran antes las variedades del trabajo, tantas fueron las lenguas en las que el género humano quedó dividido; y cuanto más excelente era el trabajo de cada cual, tanto más bárbaro y salvaje fue su modo de hablar].

${ }^{7}$ Cito de Convivio, al cuidado de G. Fioravanti, en Dante Alighieri, Opere, vol. II, Milano, Mondadori, 2014 [Convivio, edición de F. Molina Castillo, Madrid, Cátedra, 2005].

${ }^{8}$ Dante Alighieri, De vulgari eloquentia, edición bilingüe de R. Pinto, Madrid, Cátedra, 2018. 
De la mentalidad del 'Popolo', Dante denuncia en la canción, la centralidad del dinero y su indiscriminada acumulación, antinatural porque basada en un deseo que, por la misma naturaleza del dinero, non puede ser satisfecho. Esta crítica no tiene nada de nostalgia moralista hacia un feudalismo en estructural crisis de liquidez. Como resultará aún más claramente en la segunda doctrinal, la lógica del mercado, en Florencia, había transformado completamente los antiguos roles económicos y sociales, tales como podían deducirse de la antigua ideología del «Status in ordine triplex», per la que, siendo tres los grupos (ordines) socialmente activos (oratores, bellatores, laboratores), cada uno tenía una función en el conjunto social, solidariamente vinculato a los otros dos, y el dinero, cuando existía, tenía la única finalidad de facilitar el intercambio de servicios y valores de uso9. Por el contrario, Dante es tal vez el primer pensador europeo que percibe la irreversibilidad del desarrollo capitalista, o sea la imposibilidad de volver al pasado (aquel pasado que Cacciaguida, en el Paraíso, llorará como definitivamente consumado, XV-XVI), y la consiguiente necesidad de corregir, desde la política, las perversiones que en la humanidad produce el dominio descontrolado de la economía, tal como el primer desarrollo del capitalismo hacia pronosticar, y como Dante explicará con gran despliegue de argumentos en la Monarchia.

A la luz de estas consideraciones, podemos intuir los motivos que empujan a Dante a atribuir falsamente a Federico II la idea relativa a la identificación de nobleza y riqueza, antes en la canción y luego en el Convivio (esta idea es en cambio correctamente atribuida a Aristóteles en la Monarchia). En efecto, si Dante conocía el tratado aristotélico ya en el momento de escribir la canción, hecho del que no se puede dudar, hay que concluir que no se trata de un error atributivo debido a ignorancia, o de la dependencia de Dante de una fuente desconocida, sino de una falsa información lúcidamente calculada. Reconstruimos fácilmente el sentido y la finalidad de ella si consideramos los destinatarios de la canción: en el texto la crítica de la economía de mercado tiene como destinatarios el 'Popolo' florentino y los nuevos magnates del dinero, che a partire dal 1293, con los 'Ordinamenti di giustizia', han tomado el poder en Florencia. Hay que recordar, además, que dicha burguesía, bien organizada en la 'Parte Guelfa', ya había sustancialmente reducido la influencia de la antigua aristocracia en años anteriores echando a los gibelinos (la nobleza vinculada al Imperio, que con la derrota de Manfredi, en Benevento, en 1266, había sido expulsado de Italia). Indicando como 'imperial', o sea gibelina, la reivindicación de la economía de mercado, Dante puede presentar como 'güelfa', y por lo tanto legitima, su condena, frente a los que,

${ }^{9}$ Cfr. Adalbéron de Laon [?-1031], Poème au roi Robert (Introduction, Édition et Traduction par Claude Carozzi), Paris, Société d'Édition «Les belles lettres», 1979, pp. 20-21: v. 275, «Res fidei simplex, status est sed in ordine triplex»; vv. 295-297: «Triplex ergo Dei domus est quae creditur una. Nunc orant, alii pugnant aliique laborant. Quae tria sunt simul et scissuram non patiuntur». Sobre el significado histórico y antropológico de la 'ideología tripartita', remito a los clásicos estudios de Dumézil, G., L'idéologie tripartite des Indo-Européens, Bruxelles, 1958 y Mythe et épopée, I - II - III, Paris, 1968, 1971, 1973. 
gracias a esta economía, han ocupado el poder en contra del Emperador y sus aliados naturales. Si declarara la matriz aristotélica de aquella idea (sin precisar que Aristóteles no habla del dinero sino de la tierra), obtendría un efecto contrario al que se propone en la canción: legitimar en el plano filosófico aquellos valores políticoeconómicos que quiere, en cambio, desacreditar.

En el Convivio la tesis 'falsa' debe ser mantenida, porque la prosa está al servicio del texto poético: revelar que la idea sobre la nobleza de los ricos es de Aristóteles implicaría desautorizar la canción. Pero su idea del Imperio, cuando escribe el cuarto Tratado del Convivio, ha cambiado completamente: la ideología de los partidos florentinos ha perdido para él cualquier interés (Dante ha «fatto parte per se stesso»), y en cambio ha empezado a reflexionar sobre la necesidad de restaurar la autoridad imperial para reconstruir el orden político-social. Con la consueta genialidad distingue entre autoridad política y autoridad filosófica: el Emperador tiene autoridad absoluta en el plano político, y por lo tanto hay que restaurar su poder, pero no tiene ninguna en el plano filosófico, y por lo tanto hay que abogar por una activa presencia de los 'filósofos' en la gestión del estado, porque son ellos los que indican a los poderosos el camino a seguir. El Emperador Federico II, aunque digno de tanta admiración y reverencia (como se afirma en al primer Libro del De vulgari eloquentia, escrito después de los primeros tres Tratados del Convivio, pero antes del IV), se ha equivocado, en su definción de la nobleza, porque ha invadido el territorio de la filosofía, que no es el suyo (IV ix 16):

Definir la nobleza no compete al arte imperial, y no siéndolo, al tratar de ella no debemos someternos a él, y no estando sometidos a él, no estamos obligados a mostrarle reverencia.

Cuando, bastantes años después, escribe la Monarquía, el horizonte ideológico de Dante ha vuelto a cambiar: lo de que se trata ahora es de demostrar que los poderes locales (reinos y ciudades) están necesariamente corrompidos por la codicia (la blanda cupiditas), porque de ella han surgido, y que un freno a su dominio entre los hombres puede venir solo de un poder universal al que todos los poderes locales deban obediencia. De este poder universal es representante, en la tierra, por divina y providencial decisión, el Imperio romano (del cual el germánico es modernamente heredero). La afirmación aristótelica es correctamente citada (II iii iv):

Est enim nobilitas virtus et divitie antique, iuxta Phylosophum in Politicis,

y le sirve al escritor como argumento de peso filósofico para dar legitimidad a la idea de la antigüedad de la nobleza del pueblo romano, lo que le da el derecho de gobernar el mundo.

2. Una segunda alusión a la economía de mercado la leemos en la otra canción doctrinal, ella también dirigida a la aristocracia del dinero, o sea la poderosa burguesía güelfa de Florencia, de la cual se denuncia la vileza o vulgaridad de los comportamientos: 


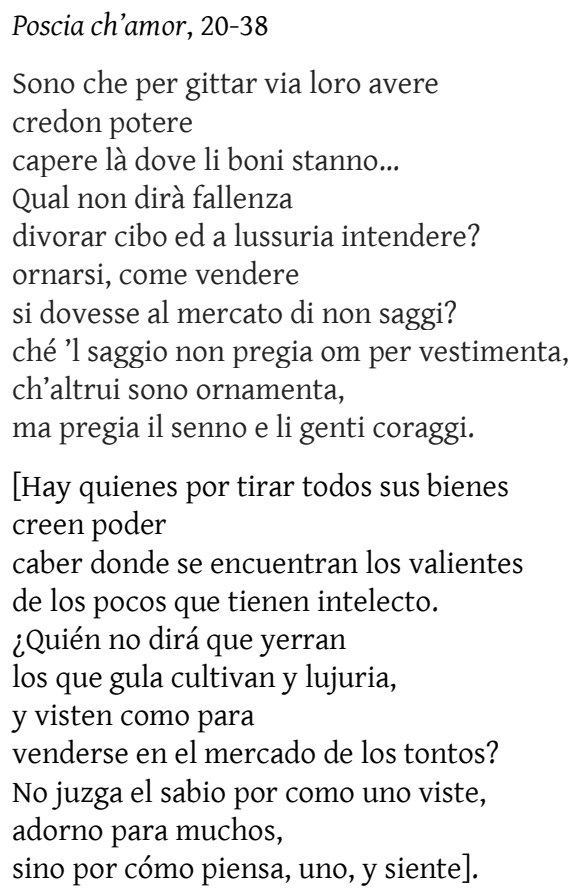

En el paso de la primera a la segunda doctrinal Dante desplaza el objetivo de la polémica de la riqueza en sí (la 'imperfección' del dinero) a las personas cuyos comportamientos son dominados por la lógica del dinero. Aquí el poeta critica con dureza no la inclinación a la acumulación, irracional porque insaciable, sino la tendencia al consumo innecesario, entendido como ostentación del lujo de parte de los que desperdician sus bienes en el mercado de los idiotas, un mercado en que no son valorados el saber y la nobleza de corazón sino los indicios externos de una nobleza aparente, como puede ser la indumentaria. En este mercado, el burgués enriquecido se pone a la venta, engañándose a sí mismo y a los que, neciamente, se dejan engañar por las apariencias. Juan Varela ha explicado muy bien que Dante intuye aquí el proceso de reificación personal al que fatalmente conduce la economía de mercado, que transforma en mercancía la persona, que se vende, socialmente, a un precio calculado a partir de su imagen ${ }^{10}$. Extraordinaria es en Dante, pues, la profética intuición de las degeneraciones del capitalismo hoy tan difusas, el hecho de que la identidad personal y el reconocimiento social dependan de la imagen visiva, o sea de fútiles apariencias, lo que equivale, en una economía de mercado, a prostituirse ('vendersi'). Obsérvese que la idea de prostitución, en Dante, acompaña siempre el concepto de codicia, como se desprende, por ejemplo, de la alegoría de la loba (avaricia) del primer canto del Infierno cuya abiecta influencia, en los humanos, se expresas con metáforas de tipos sexual (94-102):

\footnotetext{
${ }^{10}$ Cfr. Dante Alighieri, Libro de las canciones y otros poemas, Madrid, ed. Akal, 2014, pp. 312-316.
} 
ché questa bestia, per la qual tu gride, non lascia altrui passar per la sua via, ma tanto lo 'mpedisce che l'uccide; e ha natura sì malvagia e ria, che mai non empie la bramosa voglia, e dopo 'l pasto ha più fame $\mathrm{c}$ he pria. Molti son li animali a cui s'ammoglia, e più saranno ancora, infin che 'l veltro verrà, che la farà morir con doglia. [porque esta bestia que te desespera no deja paso a nadie en su camino, y persigue a cualquiera hasta matarle; tiene naturaleza tan malvada que nunca harta se queda en su codicia $\mathrm{y}$, después de comer, tiene más hambre. Con mucha gente suele copular, y muchos más serán hasta que llegue despiadado levrel, que le de muerte].

Aún más espectacular es la denuncia de los letrados (o sea, los clérigos) que prostituyen la literatura (I ix 2-3):

[los letrados italianos] si nos fijamos bien quiénes son, veríamos que ... hasta tal punto los arrastra una avaricia que les aparta de toda nobleza de ánimo (ávida de este saber), que no habrían sido receptivos a tal don [de saber]. Y para reprobarlos diré que no se les debiera llamar letrados, porque no se introducen en las letras para usarlas como se debe, sino porque les sirven para ganar dinero o dignidad, de igual forma que no debe llamarse citarista a quien tiene una cítara en casa para alquilarla, en vez de para tocarla... en cambio, la bondad de ánimo, que es la que recibe este servicio [de saber] está en aquellos que, a causa del deterioro perverso de la sociedad, han dejado la literatura en manos de los que la han convertido de señora en meretriz.

La lógica de mercado, o sea la forma en que se presenta el primer capitalismo cuando se vuelve socialmente hegemónico, implica un cambio profundo en la antropología del ser humano, que se convierte en mercancía no solo en tanto que fuerza-trabajo, como explicaría Marx, sino en tanto que sujeto moral. Para apreciar la agudeza del análisis dantiano, podemos comparar los versos que acabamos de leer con los de su maestro, Brunetto Latini, el cual también percibe el significado de ostentación que tiene el dinero malgastado en lujos, pero, alineado con los valores de su clase, o sea la rica burguesía florentina, en lugar de denunciar la perversión de estos comportamientos, los justifica en función del mantenimiento del prestigio personal (Tesoretto, 1392-1426):

Però in ogne lato

ti membri di tu' stato

e spendi allegramente; 


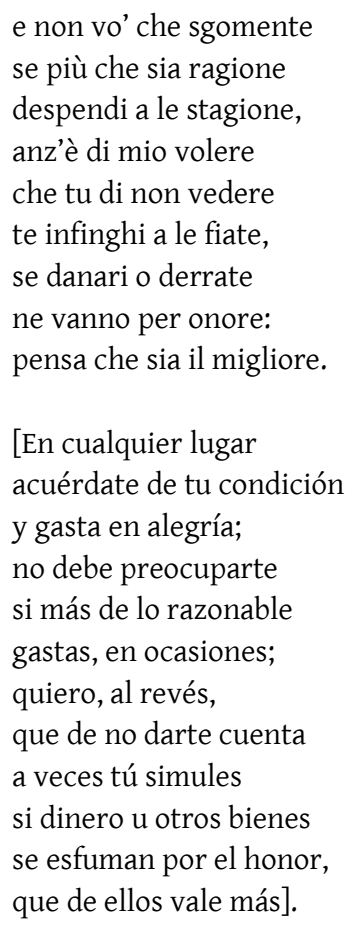

Para Brunetto el burgués sabio finge no preocuparse si gasta su dinero de manera irracional, porque la pérdida, en términos monetarios, es compensada por una ganancia mayor en términos de 'honor' (o sea reconocimiento social): se trata, entonces, de simular una mentalidad y unos comportamientos de tipo aristocrático, en sentido feudal, que considera el gasto como ostentación de poder y no como virtuosa y racional distribución de la riqueza (tema che sarà central en la canción Doglia mi reca ne lo core ardire). Dante, en cambio, sabe perfectamente que el feudalismo ha terminado, y denuncia la irracionalidad de estos «falsos y malvados caballeros» (v. 112): ostentar ficticiamente sus valores a través de las apariencias es demencia. El problema, entonces, es llenar el capitalismo, que se ha convertido en la forma económica dominante, de valores éticos, si es que es posible; la canción termina con un desesperado: «Color che vivon fanno tutti contra» [todos los que ahora viven, hacen lo contrario].

Como ha mostrado U. Carpi, para comprender esta polémica de Dante hacia la lógica del dinero es necesario tener en cuenta las denuncias de Monte Andrea, banquero arruinado y poeta, que había ya diagnosticado la enfermedad social de los florentinos, para quienes la única nobleza era la que dependía de los florines poseídos: «richezze di tesauro ora, dico / secondo il quanto, di gentilezza àn nome!» [riqueza de dinero ahora, digo, / según su cantidad, toma el nombre de nobleza ${ }^{11}$. Es justamente de la crítica

\footnotetext{
${ }^{11}$ Op. cit., p. 235.
} 
radical de Monte Andrea de la que parte la polémica de Dante, y no de la cómplice indulgencia de Brunetto Latini, que comprende y justifica en el plano ético-político los nuevos valores en los que se fundamenta el sentimiento burgués de la nobleza.

3. Mucho más amplia y articulada que en las dos doctrinales es la crítica de la economía de mercado en el Fiore, cuyos dos personajes relevantes, o sea Falsembiante y la Vecchia, describen una sociedad globalmente corrompida en sus dos vertientes antropológicas: la masculina, dominada por la sed de enriquecimiento, y la femenina, inclinada a la prostitución. Relativamente a la Vecchia, es una vez más U. Carpi el que lee la strecha relación entre el Fiore y Monte Andrea, con la sola salvedad que invierte la dirección de las influencias ${ }^{12}$.

Me detendré en el soneto 118, en el que vemos sintetizados temas que tendrán gran desarrollo en las obras sucesivas de Dante:
Falsembiante
Vedete che danari ànno usorieri,
Siniscalchi e provosti e maggiori,
Che tutti quanti son gran piatitori
E sì son argogliosi molto e fieri.
Ancor borghesi sopra i cavalieri
Son og[g]i tutti quanti venditori
Di lor derrate e aterminatori,
Sì ch'ogne gentil uon farà panieri.
E' conviene ch'e' vendan casa o terra
Infinché i borghesi siar pagati,
Che giorno e notte gli tegnono in serra.
Ma io, che porto panni devisati,
Fo creder lor che ciascheun sì erra,
E 'nganno ingannatori e ingannati.
[Veis cuánto dinero tienen los usureros
y los funcionarios de todo tipo

\footnotetext{
${ }^{12}$ «Monte Andrea avrà letto con molto consenso, se giunse a poterli leggere, i sonetti del Fiore in cui la Vecchia - che '...'l male e 'l ben sapea quantunque n'era'- insegna a Bellaccoglienza una dottrina d'amore liberata dal morbo della malinconia e condotta nel dominio della mercatantia, dove l'esser cortese e gente e bella è materia di baratto per 'conti e cavalieri e gran borgesi / Che molti fiorin d'or m'avrian dati» (ricordiamo i 'falsi cavalier, malvagi e rei' del Dante di Poscia ch'amor del tutto $m$ 'ha lasciato, la sua polemica contro quel vendere 'al mercato dei non saggi', vile e noioso, che è la negazione del valore di leggiadria): 'In poveruon no-metter già tu'amore, / Ché nonn'è cosa che poveruon vaglia: / Di lu' non puo' aver se non battaglia / E pena e povertate e gran dolore', sicché, dietro la finzione del fino e leal amore, la realtà dell'amore-mercatantia, 'Ma guarda che non fosse aconsentente / A nessun se non per la moneta'...» (op. cit., pp. 236-237).
} 


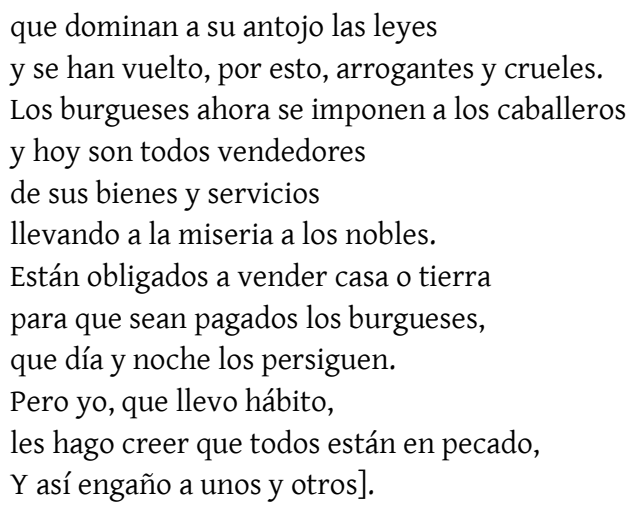

Se ha observado que este es uno de los lugarse en que el poema se aleja más de su modelo ${ }^{13}$ : en el pasaje correspondiente de la Rose de Jean de Meun se denuncia la explotación del pueblo 'minuto' de parte de la burguesía; aquí, en cambio, Dante critica el empobrecimiento de la nobleza, obligada a vender sus bienes, o sea casas y tierras, para pagar a los burgueses, que a su vez son vendedores de sus productos y servicios. Téngase en cuenta, además, que el negocio de la usura, muy extendido en Florencia, consistía en tomar como garantía de la devolución del préstamo la propiedad de inmuebles, que eran 'vendidos' al prestamista cuando el deudor no podía pagar ${ }^{14}$. Y Dante conocía perfectamente el sistema de extorsión que estaba detrás de los contratos de préstamo a usura, ya que usureros eran el abuelo (Bellincione), el padre (Alighiero), el tío (Brunetto) y el hermanastro (Francesco).

Come ya he indicado, de esta transferencia de la riqueza de una clase a otra es momento de capital importancia el decreto de los 'Ordinamenti di Giustizia' (1293) que oficializaba en el plano político la exclusión del poder de la antigua nobleza, y el consiguiente paso de una economía basada en los valores de uso y las funciones sociales a una economía basada en los valores de cambio y la lógica del mercado; la oficialización de estos valores, con el prestigio que adquieren, además del poder, los borghesi florentinos frente a los cavalieri, transforma globalmente roles e identidades sociales, en el conjunto de la ciudadanía del Comune (y el afán de los burgueses ricos por acceder al 'cavalierato' implica, como denuncia Monte Andrea, el agotamiento sociológico de la noción tradicional de nobleza). Teniendo en cuenta los dos textos, el Fiore y su modelo francés, podríamos decir que Jean considera, como objetivo polémico, las formas originarias del capitalismo comercial, y por lo tanto subraya la explotación de una clase sobre la otra; Dante, en cambio, considera formas maduras de capitalismo comercial, que en Florencia se ha convertido en capitalismo financiero, en las que la

${ }^{13}$ Il Fiore e il Detto d'amore, al cuidado de L. Formisano, en Opere di Dante, Roma, Salerno Editrice, p. 187.

${ }^{14}$ Véase, sobre esta cuestión, Sznura, F., «I debiti di Dante nel loro contesto documentario», Reti Medievali Rivista, 15/2 (2014), pp. 303-321. 
mercancía y el dinero son ya valores ideológicos socialmente dominantes para todas las clases sociales.

Lo que el texto evidencia, en efecto, es la necesidad de transformar los bienes naturales, o sea tierra y casas, en dinero, y denuncia, por lo tanto, no ya el objetivo empobrecimiento de los cavalieri (los auténticos de toda la vida, no los falsi cavalieri de la canción Poscia che Amor del tutto m'ha lasciato), sino también la conversión de esta aristocracia en sujetos económicos dentro de una lógica de mercado, hasta convertirse ellos mismos en usureros: en Inf. XVII los usureros del séptimo círculo, que comparten castigo con los sodomitas, son aristócratas florentinos y paduanos cuyos blasones están pintados en los monederos que les cuelgan del cuello. El parentesco de los usureros con los sodomitas se debe al rasgo antinatural de sus prácticas: sexuales, en los sodomitas, económicas (o 'crematísticas') en los usureros (como enseña Aristóteles).

Hay que observar, además, que Falsembiante, representante de la cultura clerical en su función de control ideológico de la sociedad (es un doctor dominico con poderes inquisitoriales), alardea de 'ingannare ingannatori e ingannati', de engañar a unos y otros (o sea tanto a la burguesía como a la aristocracia), que a él deben pagar peaje por su enriquecimiento. La feroz crítica de la simonía de papas y cardenales, en la Commedia, tiene aquí su punto de partida, en coincidencia cronológica con el pontificado de Bonifacio VIII, de quien Dante intuye perfecta e inmediatamente el propósito hegemónico sobre el Comune (y Toscana), ya que, en tanto que funcionario y político, es testigo de sus tramas, y de las colusiones con los banqueros florentinos y el rey de Francia. Invectivas como la de Par. IX 127-132:

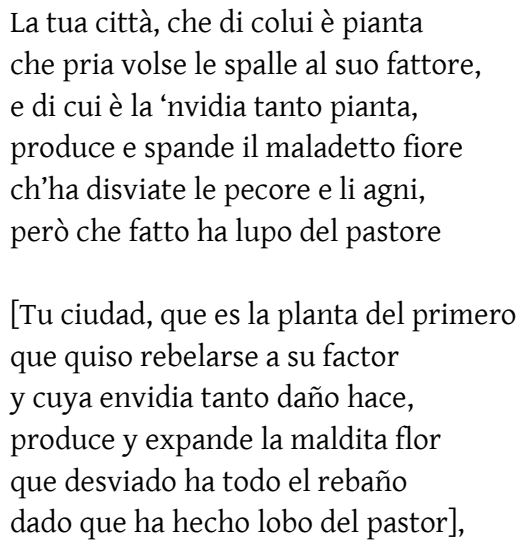

se entienden en sus profundas implicaciones tanto ideológicas como personales, a partir de la sátira mordaz del Fiore, en que la expansión del 'maladetto fiore' (el florín), o sea la difusión ecuménica de la economía de mercado, fue posible por la simonía del clero, que ha corrompido a la humanidad entera, legitimando ideológicamente, o sea en el plano religioso, la codicia. 
Las modalidades de la transformación del pastor en lobo que acabamos de ver denunciada, habían sido ya descritas por Dante en el soneto 123 del Fiore:

Falsembiante

I' sí son de' valletti d'Antecristo, Di quel' ladron' che dice la Scrittura

Che fanno molto santa portatura, E ciaschedun di loro è ipocristo.

Agnol pietoso par quand'uon l'ha visto, Di fora sì fa dolze portatura; Ma egli è dentro lupo per natura, Che divora la gente Gesocristo. Così abbiamo impreso mare e terra, E sí facciàn per tutto ordinamento: Chi no.l'oserva, di[ci]àn c[h]'a fede erra. Tanto facciàn co.nostro tradimento Che tutto 'l mondo à preso co-noi guerra; Ma tutti gli mettiamo a perdimento.

[Yo soy uno de los siervos del Anticristo, de aquellos ladrones de los que habla la Escritura que se las dan, exteriormente, de santos, pero todos son hipócritas.

Parecen ángeles bondadosos, tan suave es su aspecto, por fuera; mas dentro son lobos feroces que devoran a los auténticos cristianos. Hemos conquistado, así, el mundo entero y por doquier imponemos nuestras reglas:

el que no las observa, decimos que es herético.

Tal es nuestra conducta traicionera que todo el mundo nos odia; pero nosotros a todo el mundo arruinamos].

La fe es ahora (para Dante, como ya lo había sido para Jean de Meun) simplemente una hipócrita arma de chantaje de los prelados hacia los que no aceptan la lógica corruptora del mercado, que tiene en la Iglesia su más poderoso baluarte.

Raffaele Pinto

rpinto1951@gmail.com

Fecha de recepción: 09/11/2019

Fecha de aceptación: 23/01/2020 